\title{
A necessidade de avaliação da política de fomento à inovação tecnológica no Brasil
}

\section{The necessity for evaluation of development policy to the technological innovation in Brazil}

La necesidad de evaluación de la politica de fomento a la innovación tecnológica en Brasil

José Henrique Bassi Souza Sperancini ${ }^{1}$ Josmar Cappa ${ }^{2}$ Lindinalva Cândido Machado ${ }^{3}$

${ }^{1}$ Graduado História pela Universidade de Sorocaba (UNISO) e em Ciências Econômicas pela Universidade Estadual de Campinas (UNICAMP). Mestre e Doutor em Política Científica e Tecnológica pela UNICAMP. Professor e pesquisador do Centro de Engenharia, Modelagem e Ciências Sociais Aplicadas (CECS) da Universidade Federal do ABC (UFABC). E-mail: josehenriquesouza@yahoo.com.br

${ }^{2}$ Doutor em Economia pela Unicamp. Diretor Executivo do Instituto de Pesquisas Civitas. E-mail: josmarcappa@gmail.com

${ }^{3}$ Cientista Social pela Unicamp. Pós-graduanda em Políticas Públicas pelo Instituto de Economia da Unicamp, Campinas, SP.

E-mail: lindymach@yahoo.com.br 
Resumo: O fomento público à inovação tecnológica vem se constituindo como um dos principais fatores responsáveis pelo diferencial competitivo entre as nações. Essa importância dada ao papel do Estado no fomento tecnológico reforça a necessidade de a sociedade estabelecer formas de monitorar as estratégias e as atividades das agências públicas. Por isso a necessidade urgente de implementar formas eficazes de avaliação de resultados das ações públicas na área. Para o Brasil, essa realidade não é diferente. Esse artigo procura tratar dos principais argumentos que justificam a necessidade de o Estado brasileiro institucionalizar as práticas de avaliação de suas ações de apoio à inovação empresarial.

Palavras-chave: avaliação; política científica e tecnológica; inovação; Brasil.

Abstract: Public promotion of technological innovation is one of the main factors of the competitive differential between nations. The importance of the State in the technological promotion determine the necessity of the society to monitor the strategies and the activities of the public agencies in this field. It is urgent to implement efficient evaluations of the public actions results in this field. In Brazil, it is not different. In this paper, we look at the main arguments that justify the necessity of the government to institutionalize the evaluation of its action in private innovation.

Keywords: evaluation; science and technology policy; innovation; Brazil.

Resumen: El fomento público a la innovación tecnológica viene constituyéndose cómo uno de los principales factores responsables por el diferencial competitivo entre las naciones. Esa importancia dada al papel del Estado en el fomento tecnológico refuerza la necesidad de la sociedad establecer formas de monitorear las estrategias y las actividades de las agencias públicas. Por eso, la necesidad urgente de implementar formas eficaces de evaluación de resultados de las acciones públicas en el área. Para Brasil, esa realidad no es diferente. Ese artículo busca tratar de los principales argumentos que justifican la necesidad del Estado brasileño institucionalizar las prácticas de evaluación de sus acciones de apoyo a la innovación empresarial.

Palabras clave: evaluación; política cientifica y tecnológica; innovación; Brasil. 


\section{INTRODUÇÃO}

A justificativa do apoio público à pesquisa e à inovação empresarial é a de que tal esforço gera benefícios para o país em áreas como meio ambiente, saúde, serviços públicos, melhoria de produtos, criação de emprego e aumento na renda. Também interessa à sociedade um crescimento econômico sustentável, o que só ocorre por meio de uma estrutura empresarial dinâmica, forte, competitiva e preparada para reagir às mudanças e aproveitar novas oportunidades tecnológicas. O fomento público pode induzir o setor privado a investir em pesquisas e inovações que geram aumento da produtividade. Do mesmo modo, pode contribuir para mudanças estruturais na economia promovendo o crescimento econômico, elevando as exportações, melhorando serviços públicos e promovendo o bem-estar social.

O financiamento público estimula a execução de projetos de alto risco financeiro, mas que geram grandes benefícios sociais e que, sem o apoio público, ficariam parados. Além disso, o aprendizado relacionado à inovação é local e cumulativo. O desenvolvimento está relacionado à capacidade de o país construir um ambiente propício e uma infraestrutura favorável à difusão de tecnologias avançadas, o que pode ser estimulado pelo apoio público às atividades empresariais dirigidas à imitação, adaptação e difusão de tecnologias e técnicas organizacionais avançadas.

Este artigo pretende apresentar argumentos que justificam a necessidade de o Estado brasileiro institucionalizar práticas de avaliação de suas ações no campo do fomento à inovação tecnológica empresarial. Não basta que o Estado apoie decididamente a inovação empresarial. É preciso que o faça de forma eficiente e transparente.

A avaliação de políticas de fomento público à inovação tecnológica envolve, pelo menos, três questões importantes que nortearam a organização deste artigo também em três partes, além desta introdução. A primeira parte refere-se à compreensão dos motivos principais que levam o Estado a apoiar experiências de inovação no âmbito empresarial.

A segunda parte do artigo procura entender quais são os objetos da avaliação e como é possível medir os resultados e impactos da ação do Estado relativos ao fomento tecnológico. O processo de avaliação gera informações importantes para a prestação de contas públicas, mas também 
pode contribuir para aperfeiçoar as ações do Estado. Além disso, ajuda a melhorar o aprendizado organizacional de agências executoras e permite registrar progressos, resultados e sinais de necessidades de ações futuras.

$\mathrm{Na}$ terceira parte, o artigo procura analisar como os países economicamente desenvolvidos tratam o tema da avaliação do fomento público à inovação. O objetivo é explorar subsídios teóricos e conceituais para pensar a experiência brasileira nessa área.

\section{O DEBATE TEÓRICO SOBRE FOMENTO PÚBLICO À INOVAÇÃO TECNOLÓGICA}

Diversas fontes de dados e estudiosos apontam que a tendência de gasto do Brasil em Pesquisa e Desenvolvimento (P\&D) cresce lentamente, mas continua abaixo do nível verificado nos países ricos (ARBIX; MIRANDA, 2015; MINISTÉRIO DA CIÊNCIA, TECNOLOGIA E INOVAÇÃO [MCTI], 2015a; 2015b; ORGANISATION FOR ECONOMIC CO-OPERATION AND DEVELOPMENT [OECD], 2016a). Na figura 1, pode-se observar que o Brasil continua distante dos níveis de investimentos em P\&D do mundo quando relacionado ao Produto Interno Bruto (PIB).

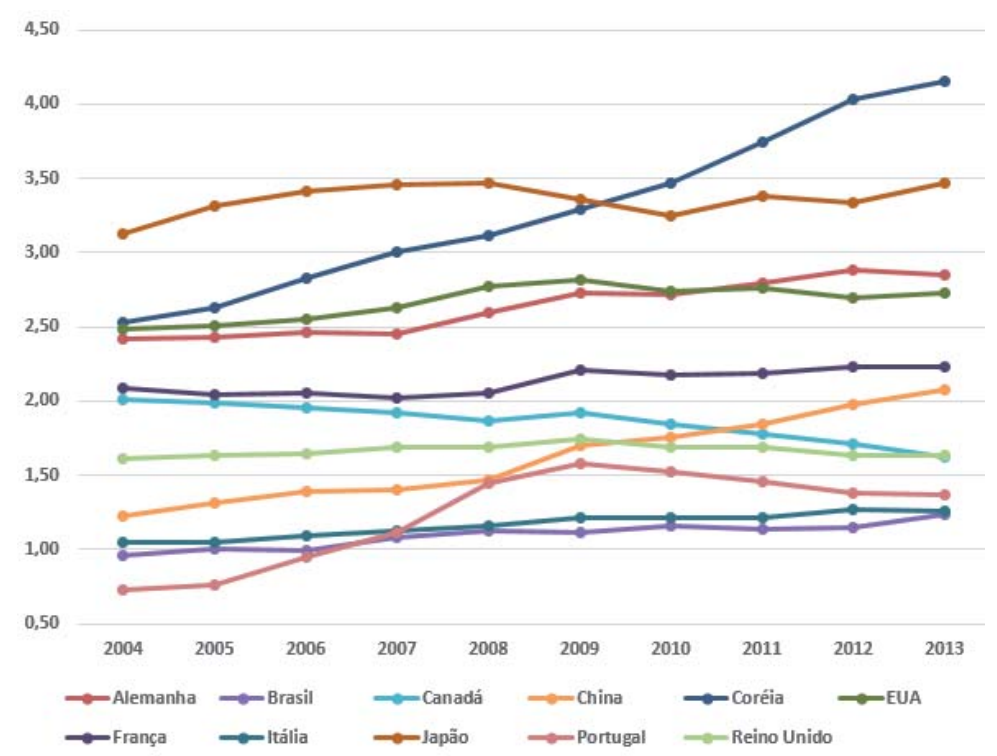

Figura 1 - Dispêndios em P\&D como \% do PIB (2004-2013) Fonte: MCTI (2017). 
Infelizmente, também não apresenta sinais de uma tendência de convergência desses investimentos como ocorreram nos casos de Portugal, entre 2004 e 2009 e, sobretudo, da China e da Coréia do Sul entre 2004 e 2013. Tal constatação pode ser observada na Tabela 1.

Tabela 1 - Dispêndios nacionais em P\&D em relação ao PIB de países selecionados: 2004-2013 (em \%)

\begin{tabular}{|l|c|c|c|c|c|c|c|c|c|c|}
\hline \multicolumn{1}{|c|}{ País } & $\mathbf{2 0 0 4}$ & $\mathbf{2 0 0 5}$ & $\mathbf{2 0 0 6}$ & $\mathbf{2 0 0 7}$ & $\mathbf{2 0 0 8}$ & $\mathbf{2 0 0 9}$ & $\mathbf{2 0 1 0}$ & $\mathbf{2 0 1 1}$ & $\mathbf{2 0 1 2}$ & $\mathbf{2 0 1 3}$ \\
\hline Alemanha & 2,42 & 2,43 & 2,46 & 2,45 & 2,60 & 2,73 & 2,72 & 2,80 & 2,88 & 2,85 \\
\hline Argentina & 0,37 & 0,38 & 0,40 & 0,40 & 0,42 & 0,48 & 0,49 & 0,52 & 0,58 & 0,58 \\
\hline Brasil & 0,96 & 1,00 & 0,99 & 1,08 & 1,13 & 1,12 & 1,16 & 1,14 & 1,15 & 1,24 \\
\hline Canadá & 2,01 & 1,99 & 1,96 & 1,92 & 1,87 & 1,92 & 1,84 & 1,78 & 1,71 & 1,62 \\
\hline China & 1,23 & 1,32 & 1,39 & 1,40 & 1,47 & 1,70 & 1,76 & 1,84 & 1,98 & 2,08 \\
\hline Cingapura & 2,10 & 2,16 & 2,13 & 2,34 & 2,62 & 2,16 & 2,01 & 2,15 & 2,00 & - \\
\hline Coréia & 2,53 & 2,63 & 2,83 & 3,00 & 3,12 & 3,29 & 3,47 & 3,74 & 4,03 & 4,15 \\
\hline Estados Unidos & 2,49 & 2,51 & 2,55 & 2,63 & 2,77 & 2,82 & 2,74 & 2,76 & 2,70 & 2,73 \\
\hline França & 2,09 & 2,04 & 2,05 & 2,02 & 2,06 & 2,21 & 2,18 & 2,19 & 2,23 & 2,23 \\
\hline Itália & 1,05 & 1,05 & 1,09 & 1,13 & 1,16 & 1,22 & 1,22 & 1,21 & 1,27 & 1,26 \\
\hline Japão & 3,13 & 3,31 & 3,41 & 3,46 & 3,47 & 3,36 & 3,25 & 3,38 & 3,34 & 3,47 \\
\hline México & 0,39 & 0,40 & 0,37 & 0,37 & 0,40 & 0,43 & 0,45 & 0,43 & 0,43 & 0,50 \\
\hline Portugal & 0,73 & 0,76 & 0,95 & 1,12 & 1,45 & 1,58 & 1,53 & 1,46 & 1,38 & 1,37 \\
\hline Reino Unido & 1,61 & 1,63 & 1,65 & 1,69 & 1,69 & 1,75 & 1,69 & 1,69 & 1,63 & 1,63 \\
\hline
\end{tabular}

Fonte: MCTI (2017).

Segundo o "Science, Technology and Innovation Outlook 2016: Brazil" (OECD, 2016b), o Brasil investe apenas 3,5\% do total de investimentos em P\&D da OCDE. Como porcentagem do PIB, os países da OCDE investem 2,38\%, quase o dobro dos 1,24\% do Brasil. Outro diferencial é que "no Brasil, grande parte dos gastos nacionais em P\&D é de responsabilidade do Estado (seja no âmbito do governo federal ou estadual)" (BONACELLI; ZACKIEWICZ; BIN, 2003).

A participação do setor público no investimento em P\&D-como porcentagem do PIB- no Brasil é ligeiramente superior à média da $\operatorname{OCDE}(0,71 \%$ para 0,61\%) (OECD, 2016b). Na verdade, no período 2012/2014, comparado ao período 2006/2008, observou-se "uma queda bastante significativa nas taxas de inovação" (DE NEGRI et al., 2016). 
Na Pesquisa de Inovação Tecnológica (Pintec) mais recente realizada pelo Instituto Brasileiro de Geografia e Estatística (IBGE, 2016), os dados também não são estimulantes. Observa-se, na figura 2, que as empresas brasileiras, sobretudo as industriais, se dedicam pouco à inovação de produto, justamente a categoria que tende a exigir maiores esforços inovativos e impulsos para inovações de processos.

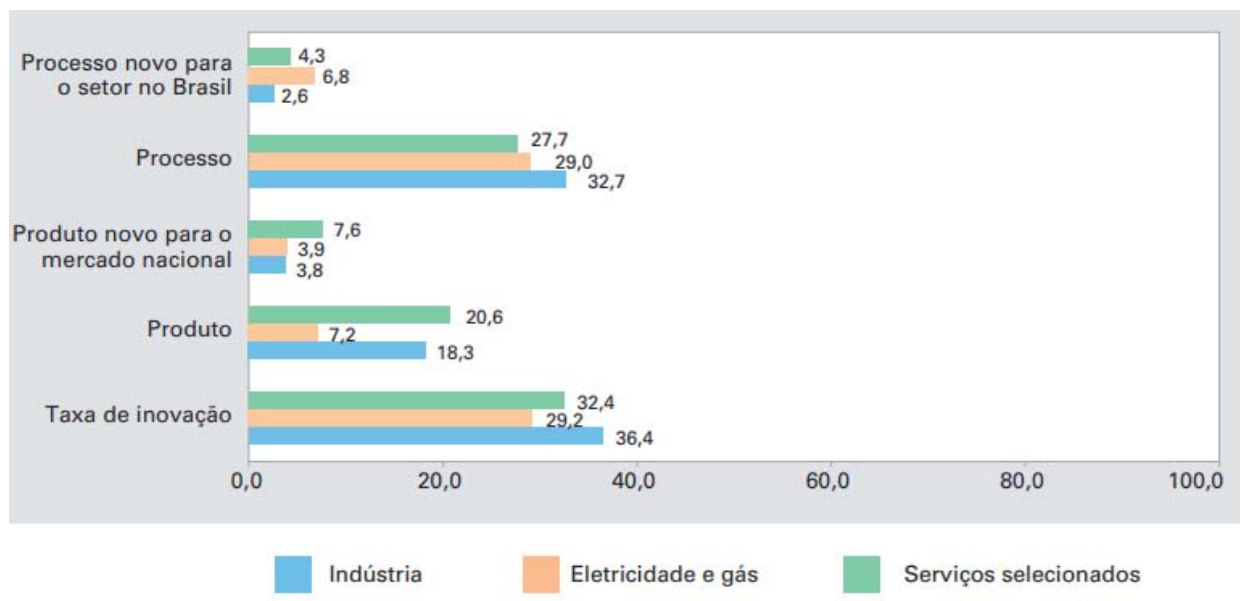

Figura 2 - Taxa de Inovação de Produto e Processo por Setores de Atividades - Brasil: 2012/2014

Fonte: IBGE (2016).

Entretanto, Furtado e Carvalho (2005, p. 73) argumentam que:

As atividades de P\&D do setor industrial brasileiro não são desprezíveis. Elas representam 32,7\% do dispêndio interno em P\&D. $O$ restante é executado por instituições públicas ou privadas de ensino e pesquisa. Embora essa proporção fique bem abaixo da dos países desenvolvidos, onde ela chega a ultrapassar os 75\% (nos Estados Unidos, por exemplo), o esforço de P\&D executado internamente pelas empresas tem um peso significativo, que define o padrão tecnológico da indústria brasileira.

Ocorre que a participação do Estado na promoção de ações de fomento à inovação empresarial não é um consenso entre os estudiosos do tema. Alguns pensadores acreditam que as falhas da intervenção estatal são maiores que as falhas naturais de mercado. Na visão de Rufín e Mahmood (2005), 
por exemplo, o envolvimento do Estado em questões tecnológicas pode ter um efeito de deslocamento e má alocação dos investimentos. Outros pensadores propõem intervenções temporárias e cadentes. Baseados, sobretudo, em Schumpeter, uma linha de pensamento vê o mercado, as instituições e o Estado como componentes fundamentais do desenvolvimento tecnológico.

A justificativa dos grupos que defendem o apoio público à pesquisa e à inovação empresarial é a de que tal esforço gera benefícios para toda a sociedade em áreas como: meio ambiente, saúde, serviços públicos, padrão de consumo e geração de emprego e renda. Também interessa à sociedade que o crescimento econômico seja sustentável, o que só ocorre por meio de uma estrutura empresarial dinâmica, inovadora, competitiva e capaz de reagir bem às mudanças na economia. O fomento público poderia induzir inversões em pesquisa, desenvolvimento e inovação que geram bem-estar social. Representam essa linha de pensamento vários modelos teóricos nos quais o Estado tem um papel chave como agente ligado às atividades de inovação. São os conhecidos casos, por exemplo, do "Triângulo de Sábato", de Jorge Sábato; da "Hélice Tríplice" de Henry Etzkowitz; dos "Sistemas Nacionais de Inovação" de Lundvall; do "Diamante" de Michael Porter; e a "Rede Técnico-Econômica" de Larédo Callon (CALLON; LARÉDO; RABEHARISOA, 1992).

Obviamente que o tipo de envolvimento do Estado na questão da inovação varia ao longo do tempo e entre países. Normalmente dependem do papel que o Estado desempenha na economia, da ideologia do partido hegemônico e das especificidades do ambiente institucional e econômico. Em alguns casos, como na Grécia e em Portugal, a participação em blocos econômicos também pode interferir favoravelmente na disponibilidade de recursos públicos para a inovação (KASTRINOS; ROMERO, 1997).

Segundo Rothwell e Dodgson (1992), o modo de o Estado interferir no mundo da inovação e do desenvolvimento varia também entre os países. Na França e no Japão, por exemplo, o Estado tem planejado, apoiado, coordenado e implementado estratégias tecnológicas. Nos Estados Unidos, Alemanha e Grã-Bretanha, o envolvimento público é menor. As forças do mercado e as estratégias das empresas são predominantes na seleção tecnológica, enquanto a política pública visa criar um ambiente favorável à inovação (Quadro 1). 


\begin{tabular}{|c|c|c|c|}
\hline & Política Científica & $\begin{array}{l}\text { Política Industrial, de } \\
\text { Inovação e Tecnológica }\end{array}$ & $\begin{array}{c}\text { Ênfase no Tamanho } \\
\text { das Empresas }\end{array}$ \\
\hline \begin{tabular}{|l} 
Década \\
de 1950 e \\
1960
\end{tabular} & $\begin{array}{l}\text { Educação científica } \\
\text { Pesquisa universitária } \\
\text { Pesquisa básica em } \\
\text { laboratórios públicos }\end{array}$ & $\begin{array}{l}\text { Política Industrial } \\
\text { Subsídios para Pesquisa e } \\
\text { Desenvolvimento (P\&D) e } \\
\text { equipamentos } \\
\text { Reestruturação industrial } \\
\text { Apoio a P\&D coletiva } \\
\text { Treinamento e educação } \\
\text { técnica }\end{array}$ & $\begin{array}{l}\text { Ênfase sobre grandes } \\
\text { firmas e aglomera- } \\
\text { ções industriais } \\
\text { Criação das } \\
\text { "flagship" nacionais } \\
\text { Fundos para P\&D de } \\
\text { grandes empresas }\end{array}$ \\
\hline $\begin{array}{l}\text { Meados } \\
\text { dos anos } \\
1970 \text { até } \\
\text { início dos } \\
\text { anos } 1980\end{array}$ & $\begin{array}{l}\text { Educação científica } \\
\text { Pesquisa universitária } \\
\text { Pesquisa básica em } \\
\text { laboratórios públicos } \\
\text { Algum interesse sobre } \\
\text { os fracos vínculos } \\
\text { universidade-indústria }\end{array}$ & \begin{tabular}{|l|} 
Política de Inovação \\
Subsídios para inovação \\
Envolvimento dos institutos \\
de pesquisa no desenvolvi- \\
mento de produtos \\
Política estatal de compra \\
para estimular a inovação
\end{tabular} & $\begin{array}{l}\text { Crescente interesse } \\
\text { pela pequena e mé- } \\
\text { dia empresa (PMEs) } \\
\text { Medidas para apoiar } \\
\text { as (PMEs) } \\
\text { Escassez de capital } \\
\text { de Risco }\end{array}$ \\
\hline $\begin{array}{l}\text { Início dos } \\
\text { anos } 1980 \\
\text { até os dias } \\
\text { de hoje }\end{array}$ & $\begin{array}{l}\text { Ênfase sobre os } \\
\text { vínculos universidade- } \\
\text {-empresas } \\
\text { Ênfase sobre pesquisa } \\
\text { estratégica nas univer- } \\
\text { sidades }\end{array}$ & $\begin{array}{l}\text { Política Tecnológica } \\
\text { Seleção e apoio à tecnolo- } \\
\text { gias genéricas } \\
\text { Crescimento na política eu- } \\
\text { ropeia de colaboração em } \\
\text { pesquisa pré-competitiva } \\
\text { Ênfase na colaboração } \\
\text { entre empresas }\end{array}$ & $\begin{array}{l}\text { Ênfase na criação de } \\
\text { empresas baseadas } \\
\text { em novas tecnolo- } \\
\text { gias } \\
\text { Aumento na dispo- } \\
\text { nibilidade de capital } \\
\text { de risco }\end{array}$ \\
\hline
\end{tabular}

Quadro 1 - Evolução da pesquisa pública e da política de desenvolvimento tecnológico na Europa

Fonte: Rothwell e Dodgson (1992).

Na França e na Itália, o envolvimento estatal já foi parte de um planejamento econômico, social, regional e nacional que servia de indicativo para o setor privado. Os objetivos da política industrial eram formulados e executados por instituições que representavam o Estado e as empresas. Outros países, como Alemanha e Dinamarca, usam instrumentos de política industrial integrados a uma política econômica focada na criação de um ambiente favorável ao desenvolvimento (ROTHWELL; DODGSON, 1992).

Também existe uma distinção relativa ao enfoque e direcionamento da política tecnológica e de inovação. Países como o Japão, Suíça e Suécia 
seguem um modelo mais orientado à difusão tecnológica (diffusion-oriented) enquanto que países como Estados Unidos, França e Grã-Bretanha são mais voltados à geração de inovações radicais (mission-oriented).

Os países mission-oriented buscam criar modernas indústrias baseadas em novas tecnologias. Tentam competir no início do ciclo de vida de uma tecnologia enfatizando o esforço heróico da ciência e tecnologia e dos grandes programas. No caso americano essa tendência foi marcante no segundo pós-guerra. Muitas das tecnologias inovadoras que impulsionaram a economia nesse período surgiram do gasto militar. Segundo Ratchford (1997), foram os casos, por exemplo, de aviões a jato; semicondutores; circuitos integrados; computadores; energia nuclear; satélites; microondas; telecomunicações; radar, antibióticos; pesticidas; novos materiais como aços especiais, titânio, plásticos, cerâmicas e novos métodos de fabricar e processar metais.

Os países direcionados à difusão tecnológica concentram esforços sobre a aquisição, difusão e assimilação de tecnologias existentes. O objetivo é elevar o valor agregado de produtos existentes, melhorando a qualidade e aumentando a eficiência produtiva, ou buscando ocupar nichos de mercado. A política tecnológica, nesse caso, se volta mais para as fases subsequentes à pesquisa e desenvolvimento como início da produção, introdução do produto no mercado, difusão de processos, serviços e infraestruturas orientadas à inovação.

No caso alemão, por exemplo, Kuhlmann (1995) destaca que a orientação para a difusão tecnológica se deve a dois fatores principais: a) o caráter descentralizado da estrutura de pesquisa científica e tecnológica; e b) a crença de que o Estado não deve dirigir a indústria, mas somente garantir um efetivo sistema de treinamento, alto nível de pesquisa básica e uma base de apoio tecnológico para a indústria. É evidente que essas estratégias de fomento público não ficam e nunca ficaram livres de restrições, dúvidas e críticas. Da mesma forma, na visão de Ratchford (1997), as pressões sobre o orçamento público tornam difícil a manutenção de altos níveis de gasto em pesquisa básica.

Alguns estudiosos acreditam que o mercado é suficiente para direcionar a inovação. O market pull seria mais importante do que o technology push. O corpo técnico do Estado seria capaz de identificar oportunidades 
tecnológicas, mas ineficiente para avaliar potencial de mercado e necessidades dos consumidores. O governo poderia fomentar a pesquisa básica, o desenvolvimento e as inovações que apresentem grande retorno social (JAFFE, 1996) - geralmente nas áreas ambiental, de saúde e segurança - evitando apoiar investimentos que podem ser recuperados em vendas futuras. Algumas áreas controversas deveriam ser estudadas caso a caso como: tecnologia espacial; pequenas empresas; medicamentos para públicos reduzidos; bens públicos oferecidos por empresas privadas; indústrias chaves para o emprego e oferta de bens estratégicos; pesquisa genérica e cooperação internacional.

Em resumo, o fomento público à inovação empresarial tem, cada vez mais, objetivado a melhoria da performance tecnológica e competitiva dos países. Tal tendência é reforçada pela nova realidade mundial do comércio (globalização, desenvolvimento dos países emergentes, uniões alfandegárias, crescimento do mercado mundial, redução do custo do transporte e da comunicação) e pela importância crescente do conhecimento para o desenvolvimento econômico (PACAGNELLA JUNIOR; PORTO, 2012), organizacional (GONZALEZ; MARTINS, 2017) e para a geração de emprego.

Como afirmam Borges, Marques e Castilho (2016), a globalização é “[...] um 'imperativo tecnológico' semelhante ao que comandou o processo de industrialização que moldou a sociedade moderna a partir da Revolução Industrial". Uma questão óbvia que deriva desse novo ambiente competitivo no qual a inovação ocupa um papel central é que os governos que se envolvem diretamente com o apoio à inovação empresarial devem possuir alguma forma de averiguar se seus instrumentos de apoio são eficientes. E mais, o sistema de avaliação dos resultados da ação pública deve procurar comprovar os resultados do direcionamento da política de inovação e desenvolvimento.

\section{FOMENTO PÚBLICO À INOVAÇÃO TECNOLÓGICA E AVALIAÇÃO DOS RESULTADOS}

Segundo o Manual de Oslo (OECD, 2005), existem dois tipos de inovação de produtos, serviços e processos. Podem surgir novos produtos, serviços e processos cujas características tecnológicas ou uso diferem sig- 
nificativamente dos anteriores por incorporarem novas tecnologias e/ou combinações de tecnologias existentes para novos usos. Também podem ocorrer mudanças tecnológicas em produtos, serviços e processos já existentes que melhoram o desempenho, a qualidade e os custos através do uso de componentes, materiais ou subsistemas de melhor desempenho.

No caso das inovações de processo, as melhorias de métodos de produção ou entrega podem envolver mudanças nos equipamentos, organização da produção ou ambos. Tais mudanças são implementadas para produzir ou distribuir novos produtos que exigem novos métodos e equipamentos ou simplesmente para melhorar a eficiência da produção e entrega. Entretanto, para ser uma inovação efetiva, a mudança deve ter sido introduzida no mercado (inovação de produto e serviços) ou utilizada em um processo de produção (inovação de processo). Portanto, segundo Plonski (2005), a inovação envolve necessariamente atividades comerciais, financeiras, organizacionais, tecnológicas e científicas.

Na verdade, realizar avaliação de esforços de P\&D é um processo complexo (BONACELLI; ZACKIEWICZ; BIN, 2003). Algumas inovações podem ser aplicadas no lançamento ou melhoria de inúmeros produtos ou processos presentes em vários setores e segmentos. Outras têm uma aplicação mais específica com poucas externalidades (ASSOCIATION FOR TECHNOLOGY IMPLEMENTATION IN EUROPE, THE [TAFTIE], 1997; 2014). Não importa os objetivos, métodos ou objetos de análise, a avaliação de resultados dos esforços de inovação é fundamental para o aprendizado dos atores envolvidos no avanço tecnológico do país.

A avaliação de resultados e impactos da pesquisa é um tema central na área de política e gestão de ciência, tecnologia e inovação. Independente dos objetos selecionados (linhas de pesquisa, tecnologias, projetos e programas) ou dos objetivos e métodos utilizados, os produtos obtidos em exercícios de avaliação, assim como a condução de tais exercícios, são fundamentais para o aprendizado coletivo dos atores envolvidos. (FURTADO et al., 2008).

Assim, identificar a capacidade que as inovações têm em gerar efeitos positivos para o país é de vital importância para agência de fomento. Sobretudo porque um dos principais objetivos da ação do Estado no fomento tecnológico é justamente buscar o máximo de geração de efeitos benéficos 
para a sociedade. Ocorre que, para avaliar tais efeitos, é preciso defini-los e padronizá-los.

Alguns estudos e manuais são úteis na descrição dos tipos de efeitos que as inovações apoiadas por agências do Estado podem gerar, na medida em que existem efeitos que são fáceis de serem percebidos ou detectados. Algumas externalidades decrescem no bojo da difusão enquanto outras se intensificam. Também existem sucessivos níveis de impactos que dependem do tipo de tecnologia, da comercialização das inovações e do grau de competitividade do segmento (OECD, 2005; TAFTIE, 1997; 2014).

Os objetivos pretendidos e alcançados pelos projetos apoiados pelo Estado podem ser denominados de efeitos diretos ou output. Tais efeitos pertencem ao domínio imediato do projeto e normalmente representam o retorno privado.

Além dos efeitos diretos, surgem outras externalidades que podem ser denominadas de efeitos indiretos, spillover, spin-off ou impactos. Essas externalidades vão além dos objetivos propostos pelos projetos extrapolando os ganhos das empresas e gerando um benefício social que pode ser considerado como taxa social de retorno dos projetos. Os efeitos indiretos geralmente se manifestam através da difusão de conhecimentos e ganhos ao longo das redes de companhias, organizações, usuários e consumidores das empresas que executam os projetos. Jaffe (1996) classifica essas externalidades em três tipos:

I) Externalidades de mercado: são os ganhos de consumidores e empresas que adquirem produtos, insumos ou bens de capital melhores, mais baratos ou mais eficientes;

II) Externalidades de conhecimento: muitos conhecimentos gerados dentro de uma empresa inovadora podem ser imitados por empresas seguidoras. Para Rufin e Mahmood (2005) esses knowledge spillovers contribuem para gerar um estoque de conhecimento sobre o qual novas firmas inovadoras podem operar. Um processo de produção mais eficiente que pode ser copiado por outras firmas. Essas podem criar valores a custo zero ou menor do que aquele que foi dispendido pela firma inovadora. Esse efeito pode, como argumenta Porter (1990), anular as vantagens competitivas conquistadas pelas empresas inovadoras; $\mathrm{e}$ 
III) Externalidades de rede: algumas tecnologias dependem, para sua aplicação, de um conjunto inter-relacionado e interdependente de tecnologias. Uma empresa isoladamente, muitas vezes, é incapaz de desenvolver todos os componentes necessários de um equipamento, por exemplo. Assim, o êxito comercial da inovação depende do sucesso individual de cada empresa que participa da rede de inovação ou da cadeia produtiva.

Termos como resultados, outcome ou results costuma se referir a todos os efeitos, diretos e indiretos, decorrentes da realização do projeto (JAFFE, 1996; TAFTIE, 1997; 2014). Representam, portanto, as consequências do próprio projeto. No que se refere à política de fomento à inovação no Brasil, o Estado poderia perseguir a criação de um sistema de avaliação que, ao menos, incorporasse os efeitos diretos. Tal necessidade é urgente já que o Estado brasileiro mantém importantes organizações de fomento à inovação tecnológica, como a Finep e o BNDES. Como demonstra Corrêa (2007), no Brasil e na América Latina, a avaliação de resultados vem adquirindo importância desde que o Banco Mundial e o Banco Interamericano de Desenvolvimento passaram a fomentá-la na implementação de reformas no serviço público (Figura 3).

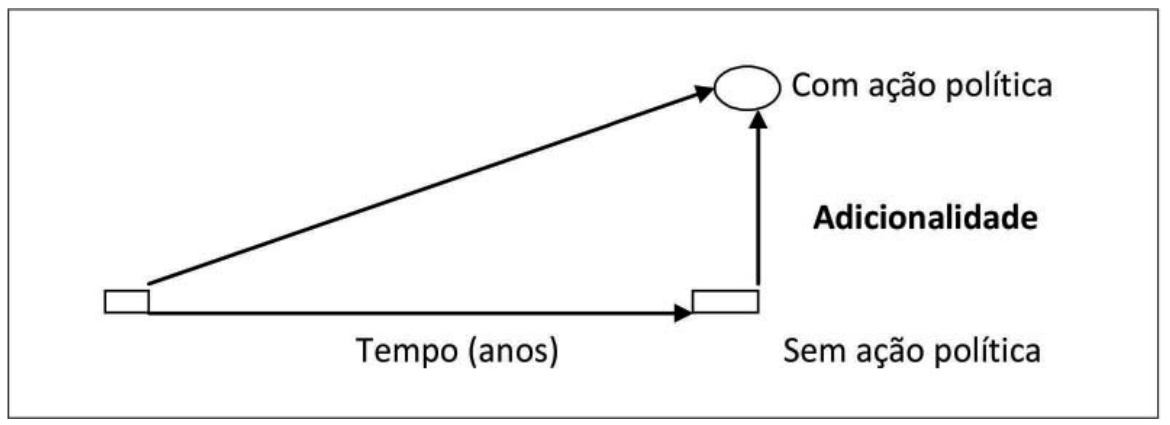

Figura 3 - O conceito de adicionalidade Fonte: Taftie (1997, p. 14).

Desse modo, é possível notar que o apoio público à inovação das empresas pode modificar o grau de desenvolvimento não apenas da empresa beneficiada, mas de cadeias produtivas ou mesmo segmentos inteiros. Ocorre que tais melhorias não apareceriam, ou se dariam em menor quantidade, ou mais tardiamente, não fosse justamente o fomento público. 
Portanto, da ação pública, deriva um benefício adicional ao processo de desenvolvimento. Tal efeito pode ser denominado de "adicionalidade".

O quadro acima ilustra o efeito desse fenômeno. Mas é possível refinar ainda mais o critério de Adicionalidade para verificar a Eficácia dos mecanismos de apoio público. A figura 4 ilustra o fato de que o apoio público deve deslocar o projeto para nordeste de tal modo que os ganhos sociais aumentem e que o projeto se torne viável do ponto de vista privado. Assim, o apoio público torna atrativo um projeto socialmente importante que permaneceria parado ou que seria executado mais lentamente pela empresa. Nesse caso, os benefícios sociais ficariam perdidos, reduzidos ou atrasados.

Na Figura 4, pode-se observar que o apoio público desloca o projeto para o quadrante no qual existe uma taxa mínima aceitável do ponto de vista empresarial. À esquerda da linha RPH os empresários não investem.

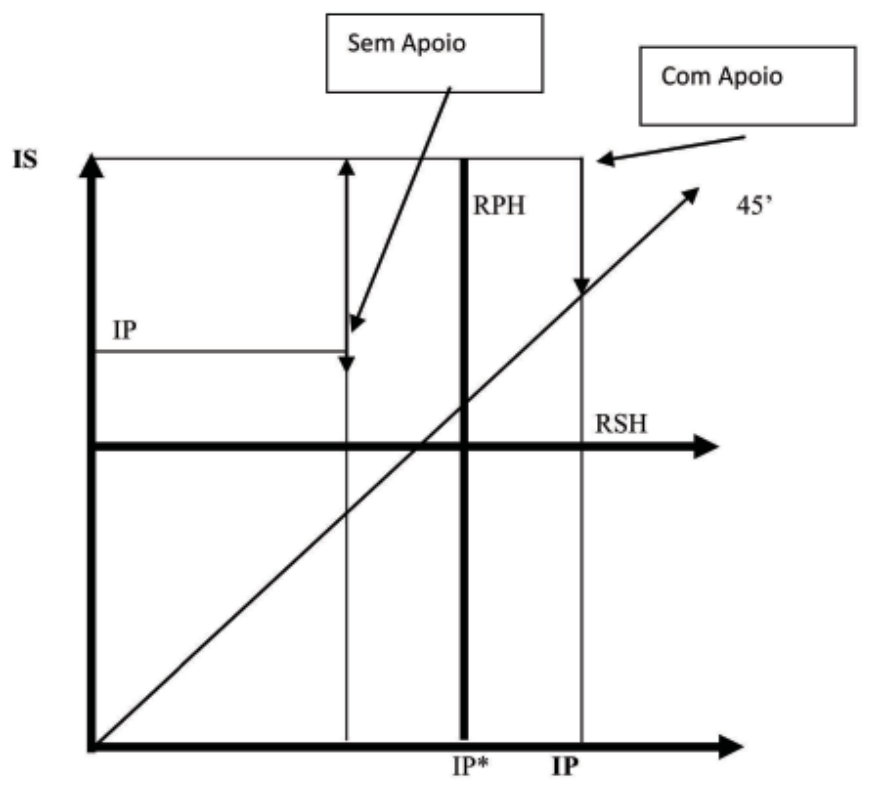

Sendo:

IS = Taxa Social de Retorno

IP = Taxa Privada de Retorno

$\mathrm{IP}^{*}$ = Taxa Privada de Retorno com Apoio Público

RSH = Taxa Social de Retorno Mínima Aceitável para a sociedade apoiar o projeto $\mathrm{RPH}=$ Taxa Privada Mínima Aceitável para a empresa executar o projeto

Figura 4 - Efeito deslocamento do apoio público

Fonte: Link e Scott (1998). 
Outro modelo que procura demonstrar que a função do apoio público é maximizar a taxa social de retorno social é dado por Jaffe (1996). Na figura 5, os projetos A, B e C geram mais retorno social do que privado. Se o apoio público visa gerar a maior taxa de retorno social possível, o projeto C é o protótipo do ideal devendo ser o primeiro a ser aprovado. Todavia o projeto $\mathrm{C}$ provavelmente seria executado pela iniciativa privada mesmo sem o apoio público devido à sua alta taxa de retorno privado. Por outro lado, os projetos A e B não seriam levados à frente a não ser que fossem estimulados pelo apoio público.

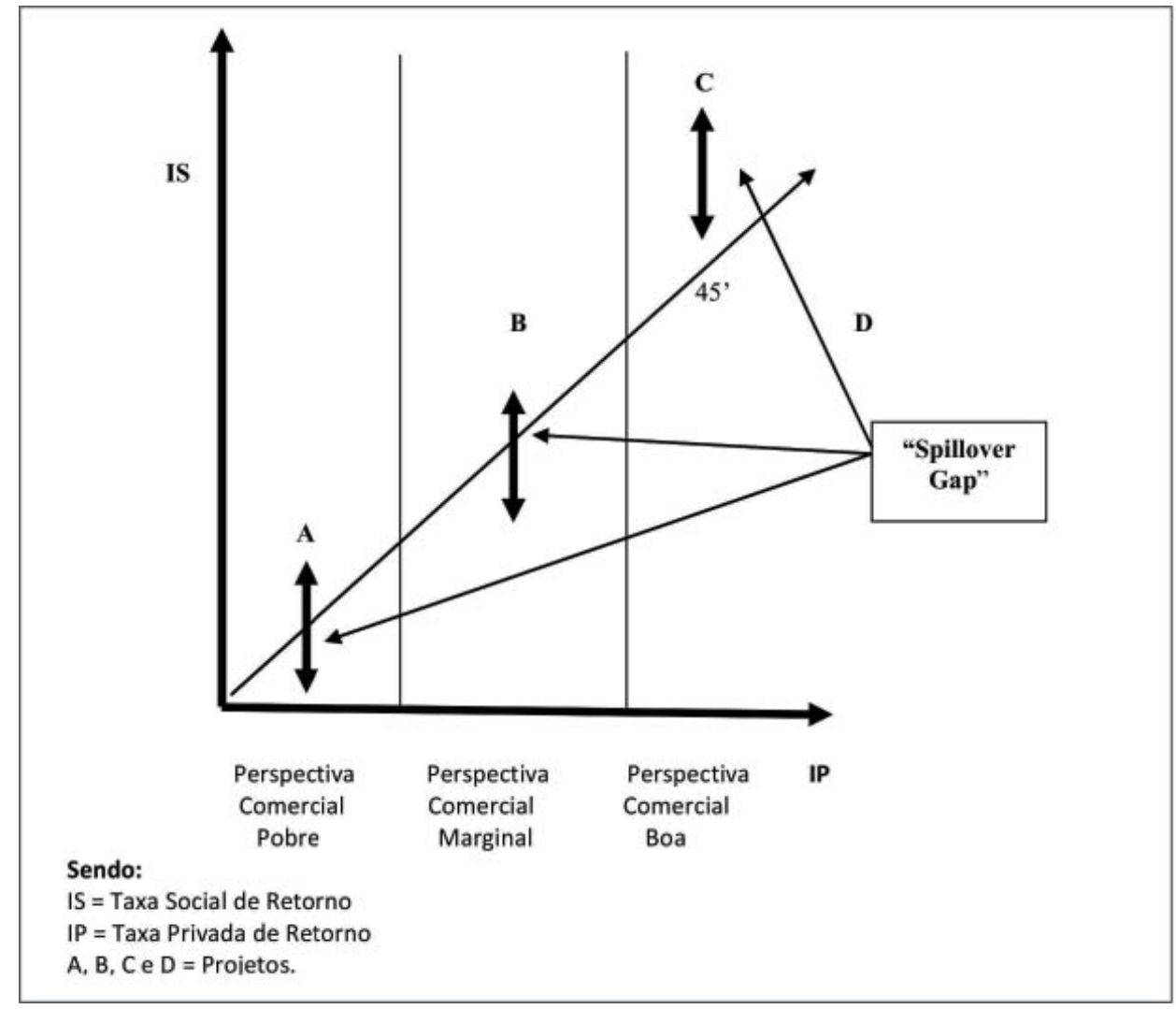

Figura 5 - Spillover gap

Fonte: Jaffe (1996). 
Nesse caso, se o objetivo da política tecnológica é gerar, não a maior taxa de retorno social por projeto, mas a maior diferença entre o ganho social e o ganho privado, então ela deve privilegiar os projetos A e B. A política pública estaria prestigiando aqueles projetos que não sairiam do papel sem sua ação, como no caso do projeto A, ou que demorariam para ser implementados por apresentarem baixo retorno privado em relação a projetos alternativos.

Desse modo, o apoio público representa um vetor que desloca os projetos executados para uma área na qual o retorno social e a atratividade privada são maiores. Essa força, entretanto, não desloca o investimento privado. O ganho privado, em muitos casos, somente se torna possível com o apoio público. Sem o apoio público, as empresas não investiriam nos projetos $A$ e B, mas apenas nos projetos $C$ e D. Como as empresas executariam tais projetos de qualquer forma, não caberia ao Estado apoiá-los já que tal apoio apenas deslocaria o investimento privado substituindo-o pelo gasto público. Não haveria, nesse caso, nenhum ganho social adicional e, portanto, nenhuma necessidade de apoio.

No caso do projeto $C$, a agência de fomento ainda teria a justificativa de que seu apoio se deve ao fato de que ele gera mais ganho social do que privado (positive spillover). Obviamente que as estimativas desses gaps spillovers são incertas e grosseiras. Em muitos casos, também é difícil identificar se o apoio público provoca o deslocamento e a substituição dos investimentos privados. No entanto, no momento da avaliação ex ante do projeto, essa preocupação pode estar presente como um critério de aprovação dos projetos ou pelo menos como um enfoque estratégico da agência.

O foco estratégico do fomento público parece ser claro. O fomento público deve dar prioridade aos projetos com altas taxas de retorno social e baixa probabilidade de deslocamento e substituição e aqueles que apresentem grande diferença entre o ganho social e privado. Assim, o Estado deve apoiar projetos que gerem benefícios sociais e para os quais seu apoio faça alguma diferença.

As medições e informações são impossíveis ou imperfeitas no que diz respeito às taxas de retorno, social e privada, sucesso dos empreendimentos e decisão das empresas de executar um projeto. O único modo 
de solucionar esse problema seria identificar os fatores responsáveis pela atratividade econômica dos projetos e aqueles responsáveis pela geração de ganho social. Jaffe (1996) observa que os ganhos de um apoio público à inovação de uma empresa se espalham por inúmeros agentes econômicos. Na figura 6, nota-se que o gasto privado em inovação gera diferentes tipos de benefícios para a empresa que o executa, para as empresas seguidoras e para os consumidores dos produtos gerados pelas empresas inovadoras e copiadoras.

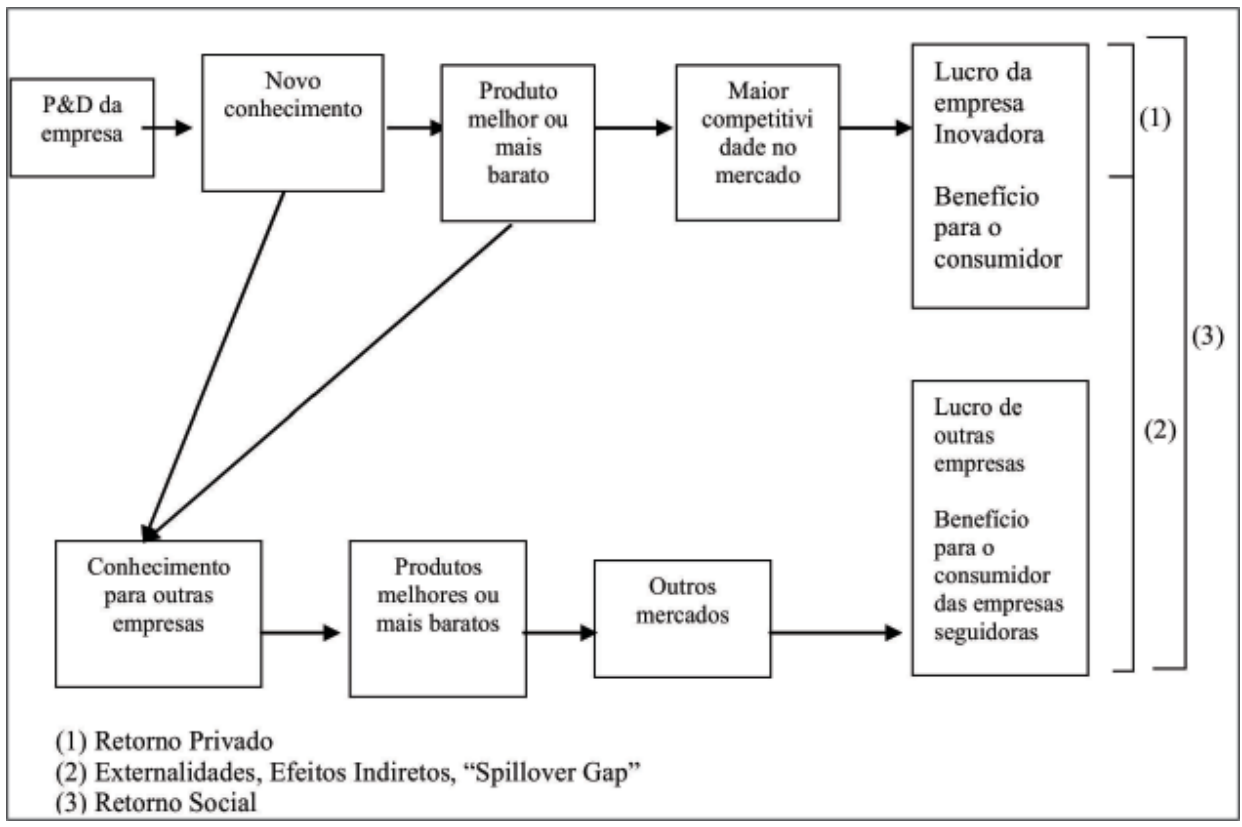

Figura 6 - Retornos privado e social da inovação

Fonte: Jaffe (1996).

Os conhecimentos gerados pela P\&D muitas vezes resultam de cooperação entre várias firmas (network spillover), ou acabam se transbordando para o mercado sendo copiados por outras empresas (knowledge spillover). Também a criação de novos produtos ou produtos melhores e mais baratos gera ganhos para os consumidores e lucros para a empresa inovadora e para as seguidoras (market spillover). 


\section{AVALIAÇÃO DAS POLÍTICAS DE INOVAÇÃO TECNOLÓGICA NOS PAÍSES DESENVOLVIDOS}

Segundo Catelli e Santos (2004, p. 424),

[...] a questão fundamental sobre como avaliar a gestão pública torna-se cada vez mais uma preocupação cotidiana dos cidadãos. Estes, estimulados a participar da vida sociopolítica, são continuamente informados, pelos meios de comunicação, sobre os impactos dos planos, das políticas, dos orçamentos, dos déficits e superávits dos governos na qualidade de vida de cada membro e setor da sociedade. Com isso, demandam cada vez mais que os gestores públicos não apenas se atenham com disciplina aos limites dos escassos recursos orçados, mas otimizem a aplicação desses recursos em políticas que atendam efetivamente as necessidades da sociedade.

Como argumenta Plonski (2005), o aumento da competitividade das economias, sobretudo nos países da OCDE tornou a política tecnológica de extrema importância. Porém, não basta a sua implementação. É preciso saber até que ponto ela atinge seus objetivos. Assim, não é de se estranhar que a preocupação que havia, nos países centrais, sobre os resultados do gasto público em ciência passou a ser direcionada à política de difusão tecnológica. Isso fez com que ganhasse espaço na agenda política a preocupação em demonstrar os resultados do fomento público.

A avaliação também se tornou um instrumento chave para maximizar a eficiência dos "Sistemas Nacionais de Inovação" como pode ser conferido nos estudos de Matias-Pereira (2008) e Taftie (1997; 2014). A burocracia pública nos países desenvolvidos tem procurado gerenciar a política tecnológica de forma profissional e analítica. Para isso vem encarando a avaliação como um instrumento a mais de auxílio à gestão e à tomada de decisão sobre alocação de recursos públicos.

Tal comportamento é condizente com o modelo institucional amplamente difundido nos países desenvolvidos. Para North, por exemplo, a chave para compreender a natureza dos mercados eficientes é o tipo de aprendizagem que as organizações adquirem para sobreviver. A forma como as organizações evoluem - interagindo com as instituições e aproveitando os benefícios das modernas tecnologias - é fundamental para obter baixos níveis de custos de transação e de produção (NORTH, 1993b). "São as 
instituições econômicas e políticas de uma sociedade (em conjunto com a tecnologia empregada) que determinam a eficiência dos mercados" (NORTH, 1993a, p. 04; 1996c, p. 08).

Para Gonzalez e Martins (2017), as organizações precisam fazer com que o conhecimento circule internamente e seja empregado em ações que resultem em algum tipo de aperfeiçoamento. Porém, em muitas atividades, o sucesso não decorre apenas de um estoque de conhecimento especializado, mas do processo de aprendizagem (ARCHIBUGI; LUNDVALL, 2001), no qual a avaliação desempenha um papel fundamental.

Porém, ao que tudo indica, o uso da avaliação só ganha força quando aumenta a estrutura de apóio à inovação e do interesse da população e do poder legislativo em acompanhar as ações do poder executivo. Tal conjunto de forças tem pressionado para que a condução dos negócios do Estado gere ações relevantes, bem sucedidas e ao menor custo possível. É provável que essa atenção pública e institucional sobre os governos, e a emergência do paradigma do "Estado Empreendedor", "Estado Gerencial" ou New Public Management, sejam fatores que reforcem a adoção de medidas legais e institucionais de avaliação das atividades do Estado no campo do fomento empresarial (CORRÊA, 2007).

Talvez, a ausência de uma "pressão externa" sobre o dinheiro público explique o fato de que alguns países com sistemas de ciência, tecnologia e inovação não muito desenvolvidos tenham iniciado mais tardiamente suas políticas de avaliação sobre o fomento público à inovação empresarial. São os casos, por exemplo, do Brasil, Portugal, Grécia, Espanha e Itália (BALLART; SUBIRATS, 1997).

Nos países desenvolvidos, a avaliação do apoio público à modernização das empresas tem procurado apreciar os objetivos, instrumentos e impactos dessa política visando maximizar seus resultados e melhorar sua gestão. A avaliação é parte de uma extensa estrutura montada para desenvolver a gestão, para auxiliar a tomada de decisão e para promover a transparência da política de fomento público. Nos EUA, por exemplo, além de haver interesse na avaliação de resultados por parte do Congresso, das Secretarias do Executivo Federal, da imprensa e de grupos empresariais, existem leis, que obrigam os programas públicos a apresentarem relatórios de resultados. 
As instituições públicas norte-americanas devem avaliar seus resultados para atender as determinações do Congresso, das Secretarias do Executivo Federal e de leis, como, por exemplo, são conhecidas pela literatura econômica, a Government Performance and Results Act, de 1993, a Federal Managers, Financial Integrity Act, de 1982, a Chief Financial Officers Act, de 1990, a Federal Financial Management Improvement Act, de 1996, a Reports Consolidation Act, de 2000 e a Improper Payments Information Act, de 2002.

Semelhante constrangimento legal obriga as instituições públicas a apresentarem relatórios sobre resultados de suas ações. Através da utilização de planejamento estratégico, estabelecimento de metas e avaliação de impactos e resultados, essas leis objetivam monitorar e dar transparência a respeito das ações públicas que têm impactos sobre a vida do cidadão. Procuram essas determinações elevar a responsabilidade, a produtividade e efetividade das agências do Estado (ENVIRONMENTAL PROTECTION AGENCY [EPA], 2007).

Outros exemplos dessa tendência foram os casos britânico e canadense. Diferentes tipos de avaliação integravam um processo de gestão visando aprovar e priorizar os programas; estabelecer objetivos; avaliar ex ante e monitorar seus projetos; avaliar os programas e descobrir lições úteis para as próximas ações (COUNCIL OF SCIENCE AND TECHNOLOGY ADVISORS [CSTA], 2001; CUNNINGHAM et al., 2001).

Essa abordagem da avaliação, segundo Guy e Arnold (1993), surgiu da preocupação do governo Tatcher a respeito do papel do Estado na política industrial e na pesquisa universitária. Alguns grandes projetos apoiados pelo Estado se mostravam verdadeiros fracassos comerciais, como no caso do Concorde o que reforçava a crítica a respeito da qualidade dos serviços públicos. O Estado deveria, portanto, ter uma postura convencional agindo somente sobre as chamadas "falhas de mercado", isto é, quando houvesse: muito risco na inovação, benefícios sociais não apropriados pelo capital, informações imperfeitas e necessidade de grandes investimentos no longo prazo.

A preocupação com os resultados das ações de governo se difundiu na Comunidade Europeia nos anos 80 e 90, associada ao novo paradigma de gestão pública denominado de New Public Management e aos conceitos de 
value for money e "adicionalidade". Caberia aos funcionários públicos zelar pela maior efetividade possível do dinheiro público que, preferencialmente, financiaria somente projetos que tivessem um efeito multiplicador e que não substituíssem investimentos privados (GABOLDE, 1998).

A prática da avaliação deveria auxiliar o encontro da melhor forma de executar as políticas estabelecidas. Os gestores públicos indagavam se os programas estavam decidindo o que fazer, sem referência às necessidades reais do país; se havia programas com objetivos imprecisos e sem metas planejadas e se a formulação de política apresentava clareza a respeito do que deveria ser feito e por que (GUY; ARNOLD, 1993).

Mais recentemente foi implementado um esforço de harmonização de conceitos, métodos e indicadores de avaliação de resultados. Tal esforço está em pleno andamento na União Europeia por conta de o bloco agregar países com características e instituições heterogêneas. Daí a necessidade de criação do Regional Innovation Scoreboard, do Global Innovation Scoreboard e do Summary Innovation Index (INNO-METRICS, 2006).

Em resumo, a montagem de um sistema de avaliação das atividades de fomento à inovação empresarial é um desafio. Entretanto, a incorporação da avaliação pelas instituições de fomento do Estado pode auxiliar a melhoria de sua gestão, transparência e a prestação de contas ao cidadão.

\section{CONSIDERAÇÕES FINAIS}

A avaliação é parte de um mecanismo de aprendizagem da formulação e execução de políticas públicas. Do estabelecimento das prioridades nacionais à execução de políticas específicas de fomento à inovação, a avaliação é capaz de gerar informações úteis para a prestação de contas e para o aperfeiçoamento das políticas públicas. Também melhora o aprendizado organizacional de agências executoras e permite registrar progressos, resultados e sinais de necessidades de ações futuras. Em resumo, a avaliação possibilita averiguar se as ações públicas são bem executadas e como podem ser melhoradas, corrigidas ou difundidas.

Obviamente que a avaliação isolada não faz sentido algum. Ela é necessariamente parte de um conjunto de atividades que incluem o planejamento, a execução de ações específicas, o desenvolvimento dos métodos 
de avaliação, a coleta e a análise de dados obtidos para auxiliar o novo planejamento. Entretanto esse longo processo não faz sentido se os dados obtidos não forem efetivamente utilizados para a prestação de contas à população, para a melhoria na performance das ações do Estado e para o aprendizado das agências públicas.

Infelizmente o Estado brasileiro vem avançando muito lentamente no que diz respeito à avaliação da política de fomento à inovação empresarial. Ainda não é possível apreciar os objetivos, os instrumentos e os impactos das políticas estabelecidas e executadas pelo Estado para detectar suas falhas, vantagens ou para melhorar sua gestão e maximizar seus resultados. Desse modo, o Estado brasileiro tem um longo caminho pela frente no campo da avaliação de resultados como ferramenta de auxílio ao aprendizado e desenvolvimento da gestão pública.

Para que o Brasil possa aprender mais rapidamente, ser comparado, contribuir e utilizar a experiência internacional no campo do fomento à inovação empresarial, também será necessário implementar formas de avaliação que possam dialogar com os métodos de avaliação executados nos países centrais. Nesse sentido, será de fundamental importância a harmonização de conceitos, métodos e indicadores de avaliação de resultados com os instrumentos de avaliação empregados nos países desenvolvidos.

Com um instrumento de avaliação estruturado pode ser possível às agências públicas melhorarem suas prestações de contas e compararem, melhorarem e divulgarem a performance e os resultados de suas ações. Também será possível elevar a responsabilidade, a produtividade e a eficiência dos programas públicos através da utilização de um planejamento mais detalhado e do estabelecimento de metas objetivas. Melhorando os critérios utilizados para estabelecer objetivos, prioridades, justificar as políticas públicas, será possível dimensionar, pelo menos em parte, os resultados alcançados e o retorno social do investimento público em inovação empresarial.

Desse modo, o contribuinte brasileiro correria menos risco com agências e programas que implementam ações desvinculadas das reais necessidades e problemas do país ou que estabelecem objetivos e metas imprecisas, sem planejamento e pouco justificáveis do ponto de vista social. 


\section{REFERÊNCIAS}

ARBIX, Glauco; MIRANDA, Zil. Inovação em tempos difíceis. Plural, Revista de Ciências Sociais, São Paulo, v. 22, n. 2, p. 18-36, 2015.

ARCHIBUGI, Daniele; LUNDVALL, Bengt-Åke. The globalizing learning economy. Oxford: Oxfor University Press, 2001.

ASSOCIATION FOR TECHNOLOGY IMPLEMENTATION IN EUROPE, THE (TAFTIE). Evaluation Reference Model. The Taftie Evaluation Network. Madri, Espanha, 2014.

. The taftie guidelines on performance indicators for evaluation and monitoring. The Taftie Evaluation Network. Madri, Espanha, 1997.

BALLART, Xavier; SUBIRATS, Joan. Science and technology policy for a medium-size industrial country: the case of Spain. Science and Public Policy, Inglaterra, v. 24, n. 3, p. 197-205, jun. 1997.

BONACELLI, Maria Beatriz M.; ZACKIEWICZ, Mauro; BIN, A. Avaliação de impactos sociais de programas tecnológicos na agricultura do estado de São Paulo. Espacios, Caracas, v. 24, n. 2, 2003.

BORGES, Pedro P.; MARQUES, Heitor R.; CASTILHO, Maria Augusta. Economia asiática: modelo para o Brasil? Contribuciones a las Ciencias Sociales, out./dez. 2016. Disponível em: <http://www.eumed.net/rev/cccss/2016/04/asia.html>.

CALLON, M.; LARÉDO, P.; RABEHARISOA, V. The management and evaluation of technological programmes and the dynamics of techno-economic networks: the case of the AFME. Research Policy, v. 21, n. 3, p. 215-36, jun. 1992.

CATELLI, Armando; SANTOS, Edilene Santana. Mensurando a criação de valor na gestão pública. RAP - Revista de Administração Pública, Rio de Janeiro, v. 38, n. 3, p. 423-49, maio/jun. 2004.

CORRÊA, Izabela Moreira. Planejamento estratégico e gestão pública por resultados no processo de reforma administrativa do estado de Minas Gerais. RAP - Revista de Administração Pública, Rio de Janeiro, v. 41, n. 3, p. 487-504, maio/jun. 2007.

COUNCIL OF SCIENCE AND TECHNOLOGY ADVISORS (CSTA). Science and technology excellence in the public service: a framework for excellence in federally performed science and technology. Ottawa: CSTA, 2001.

CUNNINGHAM, P. P. N.; MARK, B.; GLYNN, S. M.; HILLS, P. V. Measuring and ensuring excellence in government science and technology: international practices - France, Germany Sweden and the United Kingdom. Science and Technology Excellence in the Public Service (STEPS), 2001. Disponívem em: $<5 b 0 c 258 d-5 f 3 a-4 a 42-99 c 3-9 e 607 b 4943 b 1>$ 
DE NEGRI, Fernanda et al. Inovação no Brasil: crescimento marginal no período recente: análise dos dados da PINTEC 2014. Brasília, n. 34, 2016. Disponível em: <http://www.ipea.gov.br/portal/images/stories/PDFs/nota_tecnica/20161209_ nt_34.pdf>.

ENVIRONMENTAL PROTECTION AGENCY (EPA). Performance and accountability report 2007. Washington: EPA, 2007.

FURTADO, André Tosi et al. Avaliação de resultados e impactos da pesquisa e desenvolvimento: avanços e desafios metodológicos a partir de estudo de caso. Gestão \& Produção, São Carlos, SP, v. 15, n. 2, p. 381-92, maio/ago. 2008. Disponível em: <http://www.scielo.br/scielo.php?script=sci_arttext\&pid=S0104-530X200800 0200013\&lng=en\&nrm=iso>. Acesso em: 8 abr. 2017. http://dx.doi.org/10.1590/ S0104-530X2008000200013.

FURTADO, André Tosi; CARVALHO, Ruy de Quadros. Padrões de intensidade tecnológica da indústria brasileira: um estudo comparativo com os países centrais. São Paulo em Perspectiva, São Paulo, v. 19, n. 1, p. 70-84, jan./mar. 2005. Disponível em: <http://www.scielo.br/scielo.php?script=sci_arttext\&pid=S0102$88392005000100006 \& \mid n g=e n \& n r m=i s o>$. Acesso em: 8 abr. 2017. http://dx.doi. org/10.1590/S0102-88392005000100006.

GABOLDE, Jean. New challenges for indicators in science and technology policymaking: a european view. Research Evaluation, UK, v. 7, n. 2, p. 99-104, ago. 1998. GONZALEZ, Rodrigo Valio Dominguez; MARTINS, Manoel Fernando. O Processo de Gestão do Conhecimento: uma pesquisa teórico-conceitual. Gestão \& Produção, São Carlos, SP, v. 24, n. 2, p. 248-65, abr./jun. 2017 (Epub: 26 jan. 2017). Disponível em: <http://www.scielo.br/scielo.php?script=sci_arttext\&pid=S0104530X2017005001103\&Ing=pt\&nrm=iso>. Acesso em: 8 abr. 2017. http://dx.doi. org/10.1590/0104-530x0893-15.

GUY, Ken; ARNOLD, Erik. UK government pratice in science and technology evaluation. Research Evaluation, UK, v. 3, n. 3, p. 179-86, dez. 1993.

INSTITUTO BRASILEIRO DE GEOGRAFIA E ESTATÍSTICA (IBGE). Pesquisa de Inovação Tecnológica - PINTEC 2014. Rio de Janeiro, 2016.

INNO-METRICS. European innovation scoreboard 2006: comparative analysis of innovation performance. Bruxelas: European Commission, Inno-Metrics, 2006.

JAFFE, Adam B. Economic analysis of research spillovers implications for the advanced technology program. Gaithersburg: Advanced Technology Program, National Institute of Standards and Techonology, 1996.

KASTRINOS, Nikos; ROMERO, Fernando. Policies for competitiveness in less favoured regions of Europe: a comparison of Greece and Portugal. Science and Public Policy, UK, v. 24, n. 3, p. 189-95, jun. 1997. 
KUHLMANN, Stefan. Patterns of science and technology policy evaluation in Germany. Research Evaluation, UK, v. 5, n. 1, p. 23-3, abr. 1995.

LINK, Alber; SCOTT, John. Evaluating public sector R\&D: a retrospective examination of U.S. Experiences. In: APEC SYMPOSIUM ON THE EVALUATION OF S\&T PROGRAMMES AMONG APEC MEMBER ECONOMIES, 12., 1998. Anais... Nova Zelândia, 1998.

MATIAS-PEREIRA, José. Administração pública comparada: uma avaliação das reformas administrativas do Brasil, EUA e União Européia. RAP - Revista de Administração Pública, Rio de Janeiro, v. 42, n. 1, p. 61-82, jan./fev. 2008.

MINISTÉRIO DA CIÊNCIA, TECNOLOGIA E INOVAÇÃO (MCTI). Nota informativa sobre evolução dos dispêndios nacionais em C\&T e P\&D no período 2000 a 2013. Brasília: MCTI, 2015a. Disponível em:<http://www.mct.gov.br/upd_blob/0237/237332.pdf>.

. Indicadores selecionados de ciência, tecnologia e inovação Brasil 2015. Brasília: MCTI, 2015b. Disponível em: <http://www.mct.gov.br/upd_ blob/0237/237254.pdf>.

MINISTÉRIO DA CIÊNCIA, TECNOLOGIA E INOVAÇÃO. Indicadores: comparações internacionais. Recursos aplicados. Tabela 8.1.2 Dispêndios nacionais em pesquisa e desenvolvimento (P\&D) em relação ao produto interno bruto (PIB) de países selecionados, 2000-2013. 2017. Disponível em: <http://www.mctic.gov.br/index. php/content/view/2076.html>. Acesso em: 15 abr. 2017.

NORTH, Douglass C. The new institutional economics and development. Economic History 9309002, EconWPA, 1993a.

. Five propositions about institutional change. Economic History 9309001, EconWPA, 1993b.

. Institutions, organizations and market competition. Economic History 9612005, EconWPA, 1996c.

ORGANISATION FOR ECONOMIC CO-OPERATION AND DEVELOPMENT (OECD). Science, Technology and Innovation Outlook 2016. Paris: OECD, 2016a.

. Science, Technology and Innovation Outlook 2016: Brazil. (OECD) Paris: OECD, 2016b.

. Manuel d'Oslo: principes directeurs pour le recueil et l'interprétation des données sur l'innovation. 3. ed. Paris: OECD, 2005.

PACAGNELLA JUNIOR, Antonio Carlos; PORTO, Geciane Silveira. Análise dos fatores de influência na propensão à inovação na indústria paulista. Revista Brasileira de Inovação, Campinas, SP, v. 11, n. 2, p. 333-64, jul./dez. 2012.

PLONSKI, Guilherme Ary. Bases para um movimento pela inovação tecnológica no 
Brasil. São Paulo em Perspectiva, São Paulo, v. 19, n. 1, p. 25-33, jan./mar. 2005. PORTER, Michael. Vantagem competitiva. 4. ed. Rio de Janeiro: Campus, 1990.

RATCHFORD, J. Thomas. Science and technology in government and industry: whence and whiter? Technology In Society, UK, v. 19, n. 3-4, p. 211-36, ago./nov. 1997.

ROTHWELL, Roy; DODGSON, Mark. European technology policy evolution: convergence towards SMES and regional technology transfer. Technovation, Dorset, UK, v. 12, n. 4, p. 223-38, maio 1992.

RUFÍN, Carlos; MAHMOOD, Ishtiaq P. From big push to big pull: the paradox of government action. Academy of Management Review, v. 30, n. 2, p. 338-60, abr. 2005. 